Culture et histoire dans l'espace roman

\title{
La Virgen de los Sicarios: el escritor y la ciudad en el nuevo fin de siglo
}

Victoria Orella Díaz Salazar

\section{(2) OpenEdition}

\section{Journals}

Edición electrónica

URL: https://journals.openedition.org/cher/12129

DOI: 10.4000/cher.12129

ISSN: 2803-5992

Editor

Presses universitaires de Strasbourg

\section{Edición impresa}

Fecha de publicación: 30 junio 2012

Paginación: 75-86

ISBN: 978-2-35410-046-9

ISSN: $1968-035 X$

\section{Referencia electrónica}

Victoria Orella Díaz Salazar, «La Virgen de los Sicarios: el escritor y la ciudad en el nuevo fin de siglo», reCHERches [En línea], 8 | 2012, Publicado el 21 febrero 2022, consultado el 23 febrero 2022. URL:

http://journals.openedition.org/cher/12129 ; DOl: https://doi.org/10.4000/cher.12129

\section{(c) (i) (ㅇ)}

Ce(tte) œuvre est mise à disposition selon les termes de la Licence Creative Commons Attribution Pas d'Utilisation Commerciale - Partage dans les Mêmes Conditions 4.0 International. 


\title{
La Virgen de los Sicarios: el escritor y la ciudad en el nuevo fin de siglo
}

\author{
Victoria Orella díaz Salazar \\ University of Southampton
}

\begin{abstract}
T a diversidad de reacciones y lecturas, a veces claramente opuestas, que LLa Virgen de los Sicarios, del escritor colombiano Fernando Vallejo, ha suscitado en el campo de la crítica especializada es una de las cuestiones a las que se enfrenta quien decide hoy emprender un estudio de esta obra. Considerando el conjunto de esta ya abundante producción crítica, y teniendo en cuenta que me centraré en las figuras del escritor y la ciudad, me parece necesario establecer de forma sucinta el marco de la presente reflexión y situarla en relación con dicha producción.

En este sentido, en primer lugar quiero observar que el presente estudio forma parte de una reflexión más amplia sobre la narrativa de Fernando Vallejo. Por ello, si bien voy a centrarme en La Virgen de los Sicarios, y sin dejar de lado su particularidad en el conjunto de la obra de este escritor, mi perspectiva inevitablemente está marcada por una visión de conjunto. Esto quiere decir que ciertos temas presentes en el texto, lejos de desdibujarse, se perfilan con más precisión al considerar otros textos del autor y habilitan así volver a éste con otra mirada. En segundo lugar, por tratarse de un texto literario ampliamente estudiado y que ha generado lecturas encontradas, considero necesario identificar qué enfoque crítico y qué líneas temáticas se van a explorar y cuáles no dado que me parece que han sido ya analizadas en profundidad por otros. Así, aunque la representación de la ciudad formará parte del análisis en torno al tema del fracaso, no profundizaré en qué representación de la ciudad - como infierno, como laberinto, como espacio
\end{abstract}


de muerte, etc. - se construye en el texto ${ }^{1}$. Dejaré de lado, al mismo tiempo, el debate, en mi opinión poco fructífero, en torno a los discursos fascistas, misóginos y racistas del narrador y su identificación como posicionamientos ideológicos del autor. En este sentido, considero que Rory O’Bryen abre una línea más productiva para analizar los textos de Vallejo al apartarse del intento de determinar si las opiniones expresadas por el narrador se corresponden con las del autor real y centrarse en la ambivalencia entre los reclamos de verosimilitud y el explícito señalamiento de la naturaleza mediada de la representación que se realiza en el texto (2004: 195-196).

Por tanto, si bien retomaré algunos de los temas que otros investigadores han identificado previamente, como la nostalgia y la ansiedad del letrado ante la imposibilidad de "leer" la sociedad según un discurso social y cultural común (Franco 2002), o la relación entre gramática, orden y violencia (Walde Uribe 1997), enfocaré estas cuestiones desde una perspectiva en la que el carácter autoficcional del texto pasará a tener un peso fundamental, llegando así a otras conclusiones interpretativas.

Mi propósito aquí es estudiar cómo se construye una representación del fracaso a partir de la visión/apropiación que el narrador, a través de sus diversas autofiguraciones, establece de la ciudad, tomada ésta como locus privilegiado desde el que reflexionar acerca de los problemas de la nación. Con el título «La Virgen de los Sicarios: el escritor y la ciudad en el nuevo fin de siglo» me interesa poner énfasis en dos cuestiones fundamentalmente. Por un lado, la idea del fin de siglo como momento que invita a la reflexión y que, por tanto, condensa discursos que proponen una revisión del pasado y generan discursos sobre el futuro a partir de una determinada lectura del presente. Y por otro lado, al identificar a este reciente fin de siglo como "nuevo" implícitamente lo sitúo en relación con el final del siglo XIX, intentando así analizar de qué manera se trabajan en el texto temas y problemas del presente cuya genealogía se remonta a ese otro final de siglo,

1 Véanse, por ejemplo, Rory O’Bryen, 2004; Pablo Restrepo-GautierPablo, 2004, «Lo sublime y el caos urbano: visiones apocalípticas de Medellín en La Virgen de los Sicarios de Fernando Vallejo», Chasqui, vol. 33, no 1, p. 96-105; Sandro Barros, 2006, "Otherness as Dystopia: Space, Marginality and Post-National Imagination in Fernando Vallejo's La virgen de los sicarios», Ciberletras: Revista de crítica literaria y de cultura, $\mathrm{n}^{\circ} 15,2006$; Semilla Durán, M. Angélica, 2007, «Figuras de la ciudad en la literatura colombiana contemporánea: ¿Infierno o laberinto», en Teresa Orecchia-Havas (ed), 2007, Les Villes et la fin du XXe siècle en Amérique latine: Littératures, cultures, répresentations, Bern, Peter Lang, p. 55-74. 
marcado por los procesos de conformación de los estados nacionales y el inicio de la modernización.

\section{La autoficción como meta-autobiografía}

Sin adentrarme en el difícil terreno de precisar una definición de autoficción para así poder justificar plenamente la consideración de $\mathrm{La}$ Virgen de los Sicarios como perteneciente a esta categoría textual, cuestión que escaparía a los límites del presente estudio ya que tal definición es aún tema de debate, enfocaré el texto como un trabajo de escritura autoficcional a partir de una serie de características que diversos autores han identificado como rasgos de la autoficción. Para el propósito de este estudio, me centraré específicamente en la autoficción como una suerte de metaautobiografía (Villain 2009). Esta posición de la autoficción con respecto a la autobiografía en términos de comentario crítico pasará no sólo por la cuestión de las paradojas lingüísticas y ontológicas que según los estudios críticos conforman la escritura autobiográfica, sino que también, desde una perspectiva específicamente histórica y cultural, tendrá que ver con la reelaboración, a veces paródica, de ciertas autofabulaciones y mitologías en torno al escritor y a la letra que han caracterizado a gran parte de la escritura autobiográfica hispanoamericana (Molloy 1996).

En relación con esas paradojas ontológicas y lingüísticas, me interesa aquí retomar la idea según la cual en la autoficción el autor no regresa como garantía última de verdad empírica y sí como provocación, en la forma de un juego en torno a la noción de sujeto real (Klinger 2007). La autoficción pone de manifiesto el carácter textual del yo, el hecho de que se trata de un "ser de lenguaje" (Robin 1997), y al señalar los límites del lenguaje para representar al yo desemboca en una interrogación acerca de la relación entre el lenguaje y la realidad que pretende representar. Desde esta perspectiva analizaré el yo que construye el texto de Vallejo precisamente como una provocación, que instala la ambigüedad y la duda y señala la naturaleza mediada de toda representación.

En lo que respecta a la escritura autobiográfica hispanoamericana, me centraré en dos aspectos. Uno es la vacilación «entre persona pública y yo privado, $[\ldots]$, entre sujeto y patria, entre evocación lírica y registro de los hechos» que Sylvia Molloy señala como algunas de las formas bajo las cuales se manifestó «la vacilación que caracterizó (y acaso sigue caracterizando) la escritura autobiográfica en Hispanoamérica» (Molloy 1996: 14-15). 
Vacilación que, según Molloy, se relaciona con la crisis de autoridad que tiene lugar tras las guerras de independencia y que provoca en el autobiógrafo la necesidad de establecer una nueva forma de legitimar la escritura del yo en un momento marcado por el inicio de los procesos de conformación de las identidades y culturas nacionales. En ese contexto surgen las preguntas: ¿para quién se escribe? ¿qué estrategias se utilizarán para legitimar la escritura del yo? El segundo aspecto es la postura testimonial que ha caracterizado la escritura autobiográfica. Presentarse como testigo de una realidad que ya no existe aparece como una estrategia de autolegitimación: no sólo justifica el ejercicio de rememoración y su escritura sino que también da respaldo al vínculo privilegiado que insinúa entre la historia individual y la historia colectiva. En este sentido, Molloy establece la autobiografía en Hispanoamérica como «un ejercicio de memoria que a la vez es una conmemoración ritual, donde las reliquias individuales [...] se secularizan y se re-presentan como sucesos compartidos» (20).

\section{El sujeto y la nación. Entre memorator oficial y conciencia crítica}

En La Virgen de los Sicarios la vacilación señalada por Molloy entre sujeto y patria, entre historia individual e historia nacional, es trabajada de forma paródica por la vía del exceso. La identificación entre los términos, pero también la distancia que a veces se establece entre éstos, ya no se realiza de forma velada, como fruto de un calculado trabajo textual que busca validar una visión de la historia $-\mathrm{y}$ a veces un proyecto de nación- y del sujeto que escribe, sino que se vuelve explícita y, se podría decir, extrema, sujeta a las pasiones, sin admitir términos medios.

A su regreso a Medellín después de una larga ausencia, en su deambular por la ciudad el narrador comienza a constatar los efectos de la violencia, y ante el peligro que cree correr, afirma que él es «la memoria de Colombia y su conciencia» y que después de él «no sigue nada» (21). Esa fusión entre sujeto y nación se fundamenta aquí en un pasado compartido que ya no existe, que únicamente pervive como recuerdo en el sujeto que se legitima así como último, y por tanto único, testigo de otra Colombia, de la cual el presente vendría a ser una imagen degradada. Como último testigo que puede dar fe de un país anterior al desastre actual, el narrador exige al «Señor Fiscal General o Procurador o como se llame» que «con las atribuciones que le dio la nueva constitución» lo proteja (21). Aquí recordar se presenta, con cierta ironía, como un deber cívico, una acción que tiene una utilidad pública: se recuerda para conservar un pasado, y la desaparición del sujeto, 
el memorator oficial (Molloy: 132), que es en sí un documento histórico, se señala como catástrofe, ya que, dice el narrador «cuando me muera aquí sí que va a ser el acabóse, el descontrol» (21).

Esta autorrepresentación del yo, del escritor, como testigo último, se repite en otras partes del texto, aunque en lugar de fusionar sujeto y nación sustituye a esta última por la figura de la ciudad. Buscando un poco de paz y seguridad en el matadero en que se ha convertido Medellín, Fernando visita las iglesias, espacios frecuentados durante su niñez a las que por tanto afirma conocer bien. En el interior de una iglesia, el narrador vuelve a asumir la figura del testigo que preserva aquello que se ha desvanecido a través de su escritura, afirmando que «el alma de Medellín que mientras yo viva no muere [...] va fluyendo por esta frase mía» (41). Y dado que él es el último testigo, afirma: «Yo sé más de Medellín que Balzac de París, y no lo invento: me estoy muriendo con él» (41). Aquí se puede ya entrever el juego en torno a la representación que se pone en escena en el texto, a través, precisamente, de la relación entre el yo y el espacio trabajada mediante la figura del exceso.

En La Virgen de los Sicarios la escritura del yo surge motivada por una crisis en el presente desde el cual se enuncia. Se trata, en esa identificación entre historia personal y colectiva, de una crisis de doble dimensión. Crisis del individuo, ya que el yo se percibe como un ser fragmentado, marcado por la pérdida de identidad, que ruega a la Virgen el milagro de volver «a ser el que fui de niño, uno solo», «a juntar las tablas del naufragio» (31). Y desde ese presente vacío, en el que se constata la cancelación de las posibilidades y las promesas que se ofrecían al niño o al joven, se señala también la crisis en su dimensión colectiva. Colombia, dice el narrador, «se nos desbarajustó» (8), «bastó una chispa para que se nos incendiara». En el umbral de un nuevo fin de siglo, las posibilidades y las promesas de una ya no tan joven nación también se han desvanecido, dejando un presente vacío que se revela como imagen del fracaso.

Sin embargo, la identificación explícita entre el yo y la nación, entre historia individual e historia colectiva, da paso, en otros momentos, al establecimiento de una distancia extrema. Así, a su regreso a Colombia tras muchos años de ausencia y ante la situación de «guerra total» en la que vive el país, se pregunta: «¿Pero por qué me preocupa a mí Colombia si ya no es mía, es ajena?» (8), mostrando aquí que el vínculo entre el sujeto y la nación se ha roto en el presente. En este caso, la distancia física se resalta para marcar otra distancia, esta vez en términos de responsabilidad: 
Recuerdo que íbamos de bache en bache, ipum! ipum! ipum! por esa carreterita destartalada y el carro a toda desbarajustándose, como se nos desbarajustó después Colombia, o mejor dicho, como se "les" desbarajustó a ellos porque a mí no, yo aquí no estaba, yo volví después, años y años, décadas y décadas (8).

Cabría pensar que esa doble relación de identificación/distancia es una simple estrategia para desligarse de un presente signado por la violencia y la descomposición de la sociedad y vincularse a un pasado para autolegitimarse como único testigo de la verdadera Medellín, la verdadera Colombia, anterior al desastre. Sin embargo, esa posición en la que el narrador busca legitimarse se desmonta en el mismo texto. Si la crisis personal y colectiva, los cambios en la ciudad y la pérdida - de un pasado idealizado - son los hechos que ponen en marcha la escritura del yo, el yo textual es entonces un producto que surge ante una situación particular en el presente desde el que se enuncia. Desde esta perspectiva, el sujeto textual no pre-existe a la representación - tampoco el pasado -, no reenvía a un referente en la "realidad", sino que es consecuencia del acto de escritura-rememoración. Esta paradoja de la escritura autobiográfica puede leerse implícitamente en La Virgen de los Sicarios cuando el narrador afirma: "Yo no inventé esta realidad, es ella la que me está inventando a mí» (76). A través de un juego en torno al carácter ficticio de la identidad del yo en el texto, se señala la ironía que define toda representación - hacer presente precisamente aquello cuya ausencia marca - (Paul de Man 1978). El sujeto y el pasado, las ausencias que la escritura autobiográfica señala y al mismo tiempo busca re-presentar - volver a hacer presente -, se revelan en su carácter ficcional. Ambos aparecen como representaciones mediadas por la memoria y por las autofiguraciones a las que Fernando recurre en un intento, plagado de ironía, de legitimar su narración y su posición privilegiada como memorator oficial. Es en el marco del trabajo textual sobre esta paradoja, que caracteriza la escritura autobiográfica, que analizaré la interrelación entre las estrategias de autorrepresentación del yo y la representación de la ciudad y cómo desde esa interrelación se realiza una lectura del presente que implica revisar el pasado de forma crítica.

La actitud nostálgica, el trabajo de escritura-rememoración de una ciudad que se considera perdida para siempre, ha sido frecuente en la literatura latinoamericana - aunque no sólo en ésta - como consecuencia de las constantes mutaciones a las que la ciudad se ve sometida desde el inicio de la modernización. Como señala Ángel Rama, la letra, al igual que había 
venido a reparar la pérdida de las culturas orales del campo, a reconstruirlas - y en cierto sentido a inventarlas desde los afanes del presente - para que no se perdieran, se avocó a fines del siglo XIX y principios del XX a contar cómo era la ciudad antes de las profundas transformaciones tanto físicas como sociales y culturales. Esta producción literaria finisecular, que se ofrecía como simple «retrato de lo ya inexistente», no era más que «una invención ilusoria generada por el movimiento, la experiencia del extrañamiento, la búsqueda de raíces, el afán de una normatividad que abarque a todos los hombres» (Rama 1984: 154-155). Y aunque Rama se refiera a la producción de un período específico, los retratos nostálgicos de una ciudad que ya no existe, signados por la ideología y la situación de cada época y lugar, se han ido intensificando en la literatura latinoamericana con la aceleración de los cambios.

En La Virgen de los Sicarios, Fernando representa en cierto modo esa figura del escritor que se siente un extraño en su propia ciudad y que recurre al relato del pasado para señalar los cambios. A su regreso a Medellín, constata cómo los límites de la ciudad de su niñez y juventud se han expandido hasta el punto de "tragarse" a los pueblos de alrededor. Pero si de un modo general Fernando señala que la ciudad se ha tragado espacios «sagrados» de su niñez, también precisa que las comunas la han "cercado", encaramadas, amenazantes, donde antes se veían «sólo cerros y cerros y mangas y mangas» (110). Lo que era una ciudad provinciana se ha convertido, fruto de las migraciones, la explosión demográfica y la extensión del narcotráfico, en una gran urbe poblada por «tres millones y medio» de almas (31), atestada por los «infinitos carros comprados con dineros del narcotráfico» (81), contaminada por la basura que genera la «avalancha» humana y por el ruido que «es el tormento del infierno» (57).

De sus palabras se puede deducir que no son los cambios en la fisonomía de la ciudad los que generan mayor ansiedad e ira en el narrador, sino la transformación social y cultural de este espacio, aunque se hable de dicha transformación a través de la referencia a las mutaciones físicas. Los discursos apocalípticos se entrecruzan con otros discursos que hablan de la ansiedad del letrado ante el avance de las masas sobre la ciudad, cuya presencia viene a señalar la realidad de desigualdad, violencia e injusticia que durante mucho tiempo se había mantenido oculta a los ojos del ciudadano, confinada al campo. Pero en el fin de siglo, esas masas que el narrador desprecia no se identifican directamente con el campesinado que emigró a la ciudad ni con las clases bajas urbanas de la Medellín de su niñez. Se trata de unas masas 
cuyas formas de vida el letrado ya no puede leer como expresión de lo tradicional, en oposición a lo moderno, y cuya cultura ya no es la cultura popular de carácter nacional. Las formas de sociabilidad, la religiosidad, las expresiones culturales de estas masas expresan las condiciones periféricas, de atraso material, de dominio de la religiosidad católica y de violencia política en las que se ha producido la definitiva entrada en la modernidad en Colombia (Giraldo y López 1991). En esas expresiones de unos nuevos estilos de vida, el narrador, como letrado, ve los signos de una crisis que supone para él una amenaza, no ya física, sino en términos simbólicos. Aquí la escritura del yo surge entonces motivada no tanto por una crisis social - descomposición de los vínculos sociales por la violencia - o vital - el ocaso de una vida -, sino por una crisis cultural, puesto que los valores culturales desde los cuales el letrado en Colombia pretendía dar forma a la sociedad y sobre los cuales cimentó su distinción y se autolegitimó como guía espiritual han entrado en franca devaluación.

Ante esta situación aparece la figura del nostálgico. Fernando recurre, intentando reafirmar su posición social y cultural privilegiada, a la rememoración del pasado. Si bien el narrador no se extiende en el relato de su niñez, sino que ofrece breves recuerdos o referencias, a veces el recurso a estos se hace como "una forma de inversión, un gesto capitalista», ya que, como señala Molloy, «la buena administración de los productos del pasado, embellecidos por el recuerdo, se transforma en acto de poder, en concesión de privilegios» (132). No es extraño, en este sentido, que comience su relato diciendo «Había en las afueras de Medellín un pueblo silencioso y apacible» (7), confiriéndole a ese pasado una dimensión mítica - es el espacio mítico de la infancia- al ser narrado como cuento antes que como recuerdo, estableciendo así un contraste con el presente que lejos de ser paraíso perdido es un infierno sin salida. La administración de los productos del pasado también se utiliza para diferenciar y jerarquizar sus costumbres respecto a las de sus conciudadanos en el presente. Así, Fernando desprecia el nuevo fervor religioso de la juventud que encuentra al visitar Sabaneta junto con Alexis, calificando a la "peregrinación» de «devota, insulsa, mentirosa» puesto que solo acude a la Virgen a pedir. A diferencia de esa masa mentirosa, Fernando si tiene "derecho" a pedirle a la Virgen, puesto que la conoce desde su infancia, «desde el colegio de los salesianos donde estudié», lo que le permite decir: «eres más mía que de esta multitud novelera» (15). 
Otra forma de autolegitimarse como único testigo de otra ciudad y otra nación que ya no existen es a través de la figura del gramático. En un país «que tuvo tantos y tan famosos» gramáticos, el narrador se define como «el último gramático de Colombia» (50). En este sentido, Fernando es un representante privilegiado de la ciudad letrada, la que atesora la pureza del lenguaje en un país donde, durante el período de la hegemonía conservadora, como parte de su proyecto de nación, esa pureza se relacionó estrechamente con el mantenimiento del orden político (Deas 2002; Walde Uribe 1997). Como representante de esa ciudad letrada, Fernando tiene el deber de controlar la barbarie de la oralidad imponiendo el buen decir, por ello se dedica a corregir a sus paisanos y a señalar los «continuos atentados al idioma» que se realizan desde la televisión. Sin embargo, si la gramática se ha vinculado en Colombia a la política, y el ordenamiento en el terreno de la palabra pretendió servir de base al ordenamiento de la sociedad - léase aquí la ciudad -, Fernando también tiene el deber de mantener el orden en el espacio urbano. Ese orden se impone bien a través de la violencia - por medio de sus amantes sicarios- bien a través de la letra, estableciendo límites en el terreno de la representación: así, dice el narrador, para «simplificar las cosas», «bajo un solo nombre Medellín son dos ciudades: la de abajo, intemporal, en el valle; y la de arriba en las montañas, rodeándola» (82), o más adelante, propone que «se siga llamando Medellín a la ciudad de abajo, y que se deje su alias para la de arriba: Medallo» (84).

Sin embargo, Fernando emite también sus dudas acerca de la letra como vehículo privilegiado de la representación, en donde representar significa imponer un sentido, un orden, sobre el caos y la barbarie. Por ello, con gran ironía, le da la razón al ex presidente Barco, para quien «todo el problema de Colombia es una cuestión de semántica» (48). Señalando esa crisis de las letras con la misma ironía, y aludiendo a ese doble sentimiento de atracción/repulsión que en el letrado ha provocado la figura del bárbaro, Fernando confiesa que era la "pureza incontaminada de letra impresa» lo que más le atraía de Alexis, puesto que reconoce que "ipara libros los que yo he leído! y mírenmé, véanmé!» (45). Sentado frente al televisor, el joven sicario, «sin saber ni inglés ni francés ni japonés ni nada sólo comprende el lenguaje universal del golpe», y en la situación presente de «guerra total» y de predominio de los nuevos medios de comunicación de masas basados en la imagen, señala el narrador, «lo demás es palabrería hueca zumbando en la cabeza» (23). 
Si la letra impresa había sido el medio privilegiado de la intelligentsia literaria para legitimar su posición, ¿qué sucede cuando la cultura impresa pierde su «lustre» (Franco 1994)? Sobre esa condición precisamente se había fundamentado la imagen del intelectual como héroe espiritual tras las guerras de la independencia, sirviendo de base a las diversas figuras, que en diferentes épocas y con variaciones en los diferentes países latinoamericanos, fueron estableciéndose: educador, preservador de la tradición, pero también agente de cambio y constructor de utopías colectivas.

En el presente fin de siglo el sueño civilizatorio basado en la modernización y el progreso se ha desvanecido, mostrando sus promesas incumplidas o su macabro reverso, y la ciudad, como emblema de ese sueño, ha dejado de ser un «lugar virtual, del porvenir» (Ramos 1989: 50). En Medellín, señala el narrador, «las armas de fuego han proliferado y yo digo que eso es progreso, porque es mejor morir de un tiro en el corazón que de un machetazo en la cabeza» (29), o señala que el tren, en "su desmesura idiota» se alza «inacabado, detenido en sus alturas y convertido abajo en guarida de mendigos y ladrones» (113). Y si montar una empresa es imposible, puesto que con «impuestos y más impuestos» que hay que pagar no queda "con qué tapar un hueco» (45), y todo para que ese dinero se lo roben los que están en el poder, lo que si tiene futuro en Colombia es la violencia: por ello, dice Fernando, aunque Pablo Escobar haya muerto los sicarios siguen trabajando, sólo que ahora por cuenta propia, son «libre empresa, la iniciativa privada» (34).

En este contexto marcado por el fracaso de una sociedad que pone en escena el texto, el no future ha dejado de ser algo exclusivo de la juventud marginal, de los sicarios, sumidos en un presente vacío de esperanzas (Franco 1994). Desde las letras el intelectual se ha revelado incapaz de elaborar símbolos nacionales integradores, siendo la violencia el único elemento que en Colombia se ha forjado como imagen en la que la comunidad nacional, en un sentido negativo, se reconoce (Urrego 1998). Tampoco el intelectual construye ahora propuestas de un futuro colectivo.

Ese sin futuro, la constatación de un presente que escenifica el fracaso de las utopías de la civilización y la revolución, provoca por un lado el deseo de huir a otro tiempo/espacio (Heffes 2009), en este caso a la nostálgica reconstrucción de una ciudad/nación que se identifican con la niñez. Sin embargo, en La Virgen de los Sicarios esa nostalgia que implicaría la negación de un presente sin futuro, un presente que es naufragio individual y colectivo, es también cuestionada por el mismo narrador. Así, los recuerdos 
de la niñez, embellecidos, astutamente «administrados» para concederse privilegios se presentan hacia el final del relato como una «inversión» inútil teniendo en cuenta la situación del presente. Por ello, Fernando dice " $¡ \mathrm{iAl}$ diablo con [...] los recuerdos! [...] ¡Nada de nostalgias! Que venga lo que venga, lo que sea, aunque sea el matadero del presente. ¡Todo menos volver atrás!"» (97). Porque, además, qué sentido tiene esa mirada nostálgica si, dice Fernando, «Colombia cambia pero sigue igual, son nuevas caras de un viejo desastre» (12).

Para concluir, podríamos decir que Fernando es un «nostálgico reflexivo» (Boym 2002), puesto que al mismo tiempo que añora un pasado, al que idealiza, vuelve a éste con una actitud crítica. Así, en La Virgen de los Sicarios, a través de la ambigüedad y la irreverencia, se pone en escena una historia individual para analizar la historia colectiva y desenmascarar la cara oculta de las narrativas legitimadoras mediante las cuales la clase política e intelectual construyó su posición privilegiada, su poder, atribuyéndole así a ésta un rol relevante en el fracaso del proyecto de creación de una comunidad nacional que el presente refleja.

\section{Bibliografía}

Boym, Svetlana, 2002, The Future of Nostalgia, Nueva York, Basic Books.

De Man, Paul, 1979, «Autobiography as De-facement », Modern Language Notes, vol 94, n 5 , Diciembre, 1978, p. 919-930.

Deas, Malcom, 2002, «Miguel Antonio Caro and Friends: Grammar and Power in Colombia», History Workshop, no 34, 2002, p. 47-71.

Franco, Jean, 1994, «What's Left of the Intelligentsia? The Uncertain Future of the Printed Word», NACLA, vol.28, no 2, 1994, p. 16-21

Franco, Jean, 2002, Fear and loathing in the polis: the dark side of modernization, Manchester, University of Manchester, col. «Manchester Spanish \& Portuguese studies».

Giraldo, Fabio y Héctor López, «La metamorfosis de la modernidad», en Fernando Viviescas y Fabio Giraldo, Colombia: el despertar de la modernidad, Bogotá, Foro Nacional por Colombia, 1991, p. 248-310.

Heffes, Gisela, 2009, Las ciudades imaginarias en la literatura latinoamericana, Rosario, Beatriz Viterbo.

Klinger, Diana, 2007, Escritas de si, escritas do outro: o retorno do autor e a virada etnográfica: Bernardo Carvalho, Fernando Vallejo, Washington Cucurto, Joao Gilberto Noll, César Aira, Silviano Santiago, Río de Janeiro, 7Letras. 
Molloy, Sylvia, 1996, Acto de presencia. La escritura autobiográfica en Hispanoamérica, México, FCE.

O'Bryen, Rory, 2004, "Representations of the city in the narrative of Fernando Vallejo», Journal of Latin American Cultural Studies, vol. 13, 2004, p. 195-204.

Rama, Ángel, 1984, La ciudad letrada, Madrid, Fineo, 2009.

Ramos, Julio, 1989, Desencuentros de la modernidad en América Latina. Literatura y política en el siglo XIX, México, Fondo de Cultura Económica.

Robin, Régine, 1997, Le Golem de l'écriture. De l'autofiction au Cybersoi, Montreal, XYZ Editeur.

Urrego, Miguel, 1998, «Mitos Fundacionales, Reforma Política y Nación en Colombia», Nómadas, no 8, Marzo, 1998, p. 10-18.

Vallejo, Fernando, 1994, La Virgen de los Sicarios, Madrid, Alfaguara.

Villain, Philippe, 2009, L'autofiction en théorie, Chatou, Les éditions de la transparence.

Walde Uribe, Erna von der, 1997, «Limpia, fija y da esplendor: el letrado y la letra en Colombia a fines del siglo XIX», Revista Iberoamericana, vol. LXIII, 1997, p. 71-83. 